Original article

\title{
Changes in gait biomechanics as functional symptom of chondromalacia patella
}

\author{
Aljona V. Altukhova ${ }^{1}$, Sergey N. Kaurkin ${ }^{1,2}$, Dmitry V. Skvortsov ${ }^{1,2}$, Alexander A. Akhpashev ${ }^{1,4}$ \\ Nikolay V. Zagorodniy ${ }^{3,4}$ \\ ${ }^{1}$ Federal Research and Clinical Centre of Russian Federal Medical and Biological Agency, Moscow, Russia \\ 2 Pirogov Russian National Research Medical University, Moscow, Russia \\ ${ }^{3}$ N.N. Priorov National Medical Research Center of Traumatology and Orthopedics, Moscow, Russia \\ ${ }^{4}$ Peoples' Friendship University of Russia, Moscow, Russia
}

Received 18 October 2019, Revised 16 February 2021, Accepted 26 April 2021

(C) 2019, Altukhova A.V., Kaurkin, S.N., Skvortsov, D.V., Akhpashev A.A., Zagorodniy N.V.

(C) 2019, Russian Open Medical Journal

Abstract: The goal of this research was to investigate functional and biomechanical symptoms in patients with chondromalacia patella.

Material and Methods - Gait biomechanics was assessed in 35 patients with diagnosed unilateral chondromalacia patella and in 20 healthy adult controls. We recorded hip and knee movements, impact loads and temporal characteristics of the gait cycle (GC) during selfpaced walking.

Results - The temporal characteristics of gait and the impact loads remained normal in the patient population. Hip flexion amplitude decreased both on the affected $(p=0.002)$ vs. unaffected $(p=0.016)$ sides, compared to healthy control, whereas the amplitude phase increased on the affected $(p=0.012)$ vs. unaffected $(p=0.001)$ sides, versus healthy control. Hip extension and adduction-abduction amplitudes did not change significantly. Stance-phase and swing-phase knee flexion amplitudes did not change significantly. Knee extension amplitude on the affected limb increased $(p=0.015)$, and knee rotation on the unaffected limb decreased versus control $(p=0.016)$. The so-called stairstep symptom defined in the study was found in $83 \%$ of patients: in 23 patients bilaterally and in 6 patients unilaterally.

Conclusion - Chondromalacia patella affected the gait biomechanics on both sides. The changes in the kinematic patterns during the flatsurface walking were not substantial. The only pathognomonic functional symptom of the condition was the stairstep symptom.

Keywords: chondromalacia patella, gait biomechanics, knee function.

Cite as Altukhova AV, Kaurkin, SN, Skvortsov, DV, Akhpashev AA, Zagorodniy NV. Changes in gait biomechanics as functional symptom of chondromalacia patella. Russian Open Medical Journal 2021; 10: e0213.

Correspondence to Aljona V. Altukhova. Phone: +7 (916) 017-58-29. E-mail: altukhova.aa@bk.ru.

\section{Introduction}

Chondromalacia patella is a common cause of knee pain and function impairment. According to available statistics, the incidence of patellofemoral pain syndrome (PFPS) as an isolated health problem among patients at the first evaluation visit is $15 \%$. PFPS combined with other disorders occurs in $25 \%$ of patients [1, 2]. Chondromalacia patella is more prevalent in females than in males [3-5]. Without timely diagnosis and treatment, PFPS can develop into patellofemoral osteoarthritis that may require surgery.

The pathology of the patellofemoral joint is still poorly studied. New pharmacologic and nonpharmacologic methods are developed for treatment and restoration of the patellofemoral joint [6].

A few published studies investigated the effect of chondromalacia patella on gait parameters. Some authors described changes in flexion-extension amplitudes in the affected knee versus healthy control [7]. Nadeau S. and co-authors showed a decrease in knee flexion angle in patients with PFPS versus healthy control; such a decrease reduced the load on the affected joint [8]. According to Powers C.M. et al., knee flexion angle in PFPS subjects in loading response during free walking did not differ significantly from the healthy control. During fast walking, however, the mean angle in patients declined to 16.9 degrees versus 21.6 degrees in control [9]. Another study by Powers C. M. showed a slower walking speed and stride length in PFPS patients versus control [10]. This finding was also supported by other authors [11-13].

The issue of PFPS-associated changes in hip amplitudes is still debatable. Some authors describe a decrease in rotation, others argue no change $[14,15]$. Barton C.J. and co-authors examined 26 PFPS patients and compared their data with a control group of 20 healthy subjects. The authors explained the decrease in hip rotation and walking speed in patients versus healthy control by a compensatory reduction of load on the affected joint during walking [16].

However, despite the available studies of PFPS effects on gait parameters, no specific pathognomonic sign has been found yet. 
The goal of this study was to assess the functional and biomechanical symptoms in patients with chondromalacia patella.

\section{Material and Methods}

\section{Study groups}

The patient group included 35 subjects with unilateral chondromalacia patella. The inclusion criteria for patients were as follows: anterior knee pain of unclear etiology; absence of X-ray and MRI evidence of patellofemoral osteoarthritis. The exclusion criteria for patients were as follows: presence of X-ray and MRI evidence of patellofemoral arthrosis; patellofemoral dysplasia; high or low position of the patella; lobular patella; damaged menisci, hyaline cartilage and/or ligaments of the knee; inflammatory process in the knee.

There were 20 females and 15 males in the patient group; their mean age was 33.6 years (ranging 22 to 67 ).
The control group included 20 adult healthy subjects, 14 males and 6 females. Their mean age was 29.7 years.

\section{Methods of biomechanical study}

Biomechanical gait analysis was performed according to the procedure described in our earlier study [17]. Five sensors of a IMU mocap complex were placed on the sacrum, the upper third of each thigh and the lower third of each leg and fixed with special cuffs. Walking movements and temporal parameters were then recorded while the subject was walking a distance of 10 metres at a self-chosen speed. For the subsequent analysis, we derived gait cycles from accelerometer data, calculated mean goniometry for hip and knee movements during the gait cycle and calculated the temporal parameters of the gait cycle. Thus, we obtained goniometry of hip and knee motions in three mutually perpendicular planes and vertical acceleration curves for the shinfixed sensors.

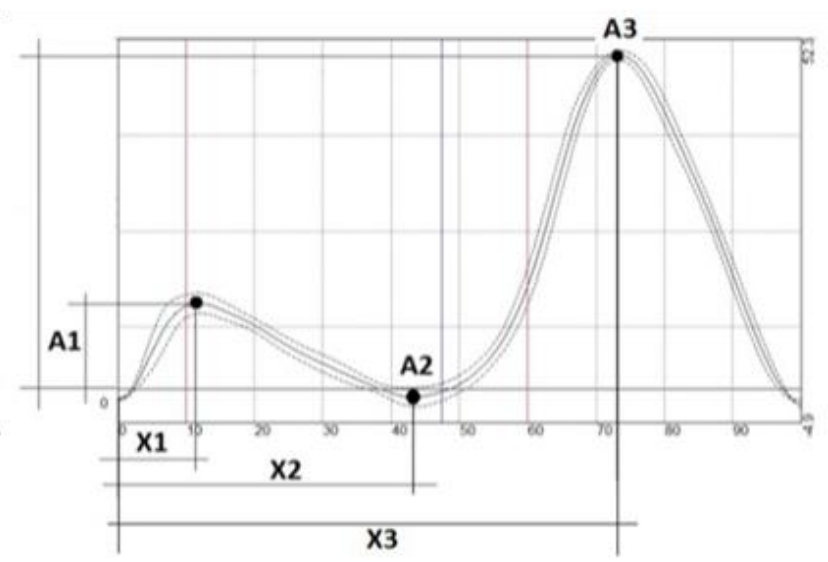

Figure 1. Measured amplitudes $\left(A, T_{a}\right)$ and phases $\left(X, T_{x}\right)$ in hip (left graph) and knee (right graph) goniometry.

Table 1. Temporal parameters of gait cycle and load amplitude at the beginning of the stance phase

\begin{tabular}{lccc}
\hline Parameter & Affected & Unaffected \\
\hline GC & $1.2(1.1,1.2), \mathrm{p}=0.386$ & $1.1(1.1,1.2), \mathrm{p}=0.262$ & Control \\
SDS & $49.9(49.2,50.3), \mathrm{p}=0.916$ & $50.0(49.3,50.7), \mathrm{p}=0.305$ & $50.1(4.1,1.2)$ \\
Load & $-1.7(-1.8,-1.6), \mathrm{p}=0.624$ & $-1.7(-1.8,-1.6), \mathrm{p}=0.377$ & $-1.7(-1.8,-1.6)$ \\
\hline
\end{tabular}

Data presented as mean with low and upper quartiles - Me (LQ, UQ). p-level, comparition with control group.

Table 2. Hip movement amplitudes

\begin{tabular}{|c|c|c|c|}
\hline Parameter & Affected & Unaffected & Control \\
\hline$\overline{T_{x 1}}$ & $5.7(4.1,7.6), p=0.012$ & $6.5(4.6,9.8), p=0.001$ & $4.3(1.5,5.2)$ \\
\hline $\mathrm{T}_{\mathrm{a} 1}$ & $21.7(18.7,25.3), p=0.002$ & $22.2(19.4,26.4), p=0.016$ & $27.4(23.1,29.4)$ \\
\hline$T_{x 2}$ & $56.6(55.3,57.6), p=0.500$ & $56.8(55.6,58.0), p=0.164$ & $56.0(54.2,57.6)$ \\
\hline $\mathrm{T}_{\text {adduc. }}$ & $14.2(12.4,17.1), p=0.377$ & $14.0(11.0,16.9), p=0.675$ & $13.1(10.3,17.6)$ \\
\hline $\mathrm{T}_{\text {rot. }}$ & $12.1(9.8,14.4), p=0.820$ & $10.6(7.7,14.5), p=0.294$ & $13.0(8.7,15.9)$ \\
\hline
\end{tabular}

Data presented as mean with low and upper quartiles - Me (LQ, UQ). p-level, comparition with control group.

Table 3. Knee movements

\begin{tabular}{|c|c|c|c|}
\hline Parameter & Affected & Unaffected & Control \\
\hline$\overline{x 1}$ & $17.1(16.3,18.2), p=0.643$ & $16.8(15.5,18.5), p=0.546$ & $16.9(14.9,18.3)$ \\
\hline a1 & $19.3(15.0,22.1), p=0.552$ & $21.1(16.1,22.7), p=0.868$ & $19.1(17.5,23.4)$ \\
\hline$x 2$ & $41.3(39.4,45.3), p=0.088$ & $43.9(40.9,45.3), p=0.965$ & $44.1(42.3,45.2)$ \\
\hline$x 3$ & $73.6(72.9,75.3), p=0.868$ & $74.7(73.1,75.5), p=0.220$ & $74.2(73.1,75.1)$ \\
\hline a3 & $67.9(64.5,72.2), p=0.582$ & $67.0(63.5,70.7), p=0.340$ & $68.3(65.7,72.2)$ \\
\hline Adduction & $15.3(12.0,19.2), p=0.930$ & $16.2(10.9,20.9), p=0.637$ & $15.6(12.0,23.9)$ \\
\hline Rotation & $17.9(15.0,23.5), p=0.495$ & $15(12.9,19.7), p=0.016$ & $19.9(14.9,23.9)$ \\
\hline
\end{tabular}

Data presented as mean with low and upper quartiles - Me (LQ, UQ). p-level, comparition with control group. 


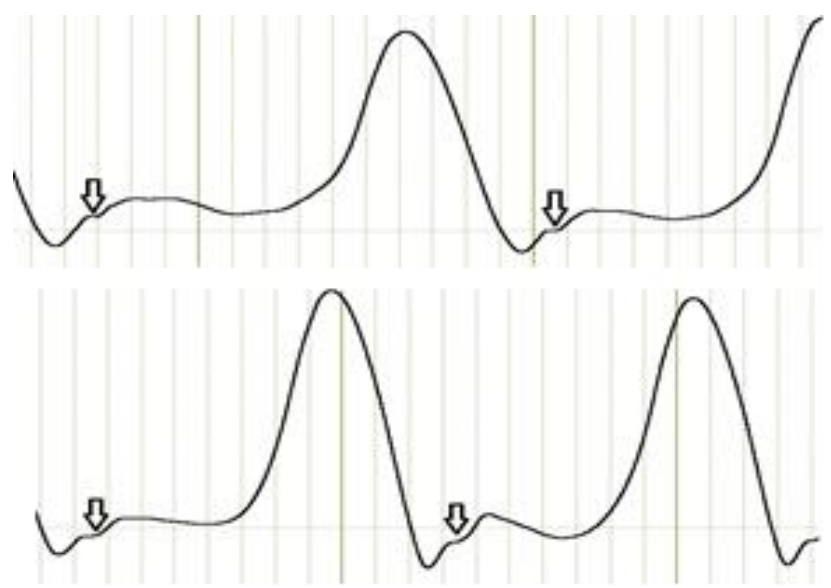

Figure 2. The stairstep symptom is marked with an arrow.

Eight gait cycles were evaluated for each subject. We did not assess the variability of parameters during the steady-state walking at a self-chosen pace because it was low in subjects of our patient group even with mild functional disorders [18-20].

\section{Measured variables}

The following temporal variables were assessed: gait cycle (GC, seconds); stance phase (SP, \% of GS); double support phase (DS, \% of GS); first double support phase (DS1, \%); second double support phase (DS2, \%); single support phase (SS, \%); start of second double support, defined as the time period from the start of GC until the heel strike of the opposite foot (SDS, \%).

Impact load was assessed by the variable 'Load' measured in g's (acceleration of gravity) at the beginning of the stance phase.

Movements of the joints were assessed as follows (Figure 1): for hip flexion-extension, we recorded maximum flexion amplitude at the beginning of $S P\left(T_{a 1}\right.$, degrees) and the phase of the amplitude $\left(T_{x 1}, \%\right.$ of $\left.G C\right)$, as well as maximum extension amplitude ( $T_{a 2}$, degrees) and its phase $\left(T_{x 2}, \%\right.$ of $\left.G C\right)$.

For knee flexion-extension movements, we recorded the amplitude and the phase of first flexion ( $\mathrm{A} 1$ and $\mathrm{X} 1$, respectively), the amplitude and the phase of extension ( $A 2$ and $X 2$, respectively), and the amplitude and the phase of second flexion with a maximum in the swing phase ( $\mathrm{A} 3$ and $\mathrm{X} 3$ ).

For abduction-adduction and rotation movements of both joints, we recorded total and a maximum amplitude over the GC.

\section{Statistical analysis}

The collected data were processed by standard ANOVA using Statistica 12 software. Medians and quartiles (25\% percentile; $75 \%$ percentile) were calculated. The normality of data distribution was not verified due to small sample size; therefore, the significance of the differences was analyzed using the Wilcoxon Mann-Whitney test, with $p<0.05$ set as the level of statistical significance. Patient data obtained for the affected vs. unaffected sides were compared with the relevant data from the healthy controls.

\section{Results}

The results of the biomechanical study are presented in Tables 1-3. Table 1 presents temporal parameters of gait cycle and impact loads.
The temporal parameters of gait cycle and the impact loads remained normal on both affected and unaffected sides.

The hip joint data in Table 2 shows a significant decrease in flexion amplitude $\left(T_{a 1}\right)$ versus control both on affected $(p=0.002)$ and unaffected $(p=0.016)$ sides at the beginning of the support phase. In addition, the amplitude phase $\left(T_{x 1}\right)$ on the affected $(p=0.012)$ and unaffected sides $(p=0.001)$ was significantly prolonged compared with control. The amplitude of hip joint extension $\left(T_{\mathrm{a} 2}\right)$ did not change significantly. Adduction-abduction ( $T_{\text {adduc. }}$ ) and rotation ( $\left.T_{\text {rot. }}\right)$ movements also showed no change.

The first knee flexion amplitude (A1) and the maximum swingphase amplitude (A3) did not change significantly. The extension amplitude during the single support phase (A2) was significantly increased on the affected limb compared with healthy control $(p=0.015)$.

Abduction-adduction movements showed no significant changes as well. Rotation movements on the unaffected side were significantly reduced compared to healthy control $(p=0.016)$.

Initial examination of the patient knee goniometry revealed a specific feature that we called the stairstep symptom. The stairstep on the curve reflects a short interruption in a first flexion of the joint (Figure 2).

The subsequent analysis for the symptom prevalence among the study patients showed that $83 \%$ of the patients had the stairstep symptom either on both sides (23 patients) or on the affected side only ( 6 patients), while another 6 patients did not have the symptom. Thus, the stairstep symptom may be associated with the presence of chondromalacia patella.

\section{Discussion}

The results of the biomechanical analysis of walking, as well as of hip and knee movement, showed minor functional differences between healthy controls and patients, both on the affected and unaffected sides.

Flexion in both hip joints was slightly reduced. Maximum flexion at the beginning of the stance phase occurred significantly later and also on both sides. Although insignificantly, both symptoms reduced the walking speed in this study, which was consistent with literature data $[9,16,21]$. We did not find any changes in hip adduction-abduction and rotation movements. Yet, some authors [15] noted a change in hip rotation amplitude, which was a sign of developing gait abnormalities in patients with PFPS. However, the applied model and marker placement in that study did not allow proper recording of hip rotation movements. Besides, the study differed from ours in design, because the walking was done on a treadmill.

According to our data, patients had functionally normal movements in both knees. Yet, the available literature describes changes in flexion-extension amplitudes of the affected knee [15]. P. Levinger and W. Gilliard [22] reported the presence of certain changes in gait biomechanics parameters in such patients. However, their study methodology used data of a different type and it was not possible to compare their findings with ours.

Thus, the analysis of standard gait biomechanical parameters failed to detect any specific pathognomonic symptoms caused by the affected joint, with the only exception of the stairstep symptom. The reason why the knee begins to behave this way requires a further study. So far, we can assume that at the very beginning of the stance phase, when the flexion has just started, 
there is an obstacle to further flexion, e.g., incongruity of articular surfaces or a pain syndrome, which briefly and transiently interrupts the joint movement.

\section{Conclusion}

Chondromalacia patella affects the gait biomechanics on both sides, affected and unaffected. The changes in kinematics while walking on a flat surface were not substantial, without significant abnormalities and functional asymmetries. The only functional symptom that could be associated with chondromalacia patella was the stairstep symptom. According to our data, it remains unclear why the symptom is more often detected on both sides. Whether it is an early symptom or the well-known phenomenon of a healthy limb repeating the pattern of movements of the affected limb [23] should be a subject of further research.

\section{Conflicts of Interest}

The authors declare no conflicts of interest.

\section{Ethical approval}

All study procedures involving human subjects were performed in accordance with the ethical standards of the institutional and/or national research committee and with 1964 Declaration of Helsinki and its later amendments or comparable ethical standards.

\section{References}

1. Kulyaba TA, Kornilov NN. Chondromalacia and other injuries of the cartilage of the knee joint. (M94.2, M94.8) Clinical recommendations. Ministry of Health of the Russian Federation 2016; 36 p. Russian. http://kokb45.ru/wp-content/uploads/2018/06/Hondromalyatsiya-idrugie-povrezhdeniya-hryashha-kolennogo-sustava.pdf.

2. Akilzhanov KR, Zhanaspaev MA. Diagnosis of orthopedic pathology of patellofemoral joint. Literature review. Science and Healthcare 2018; 20(5): 31-41. Russian. https://www.elibrary.ru/item.asp?id=36793675.

3. Vora M, Curry E, Chipman A, Matzkin E, Li X. Patellofemoral pain syndrome in female athletes: A review of diagnoses, etiology and treatment options. Orthop Rev (Pavia) 2017; 9(4): 7281. https://doi.org/10.4081/or.2017.7281

4. Habusta SF, Coffey R, Ponnarasu S, Griffin EE. Chondromalacia Patella. 2020 Oct 27. In: StatPearls. Treasure Island (FL): StatPearls Publishing. 2021. https://pubmed.ncbi.n/m.nih.gov/29083563.

5. Boling M, Padua D, Marshall S, Guskiewicz K, Pyne S, Beutler A. Gender differences in the incidence and prevalence of patellofemoral pain syndrome. Scand J Med Sci Sports 2010; 20(5): 725-730. https://doi.org/10.1111/j.1600-0838.2009.00996.x.

6. Prokhorova ES. Correction of functional disorders of the musculoskeletal system in patients with patellofemoral pain syndrome. PhD Dissertation. Moscow, Russia. 2018; 116 p. Russian. https://www.elibrary.ru/item. asp?id=42613366.

7. Farrokhi S, O'Connell M, Fitzgerald GK. Altered Gait Biomechanics and Increased Knee-Specific Impairments in Patients with Coexisting Tibiofemoral and Patellofemoral Osteoarthritis. Gait Posture 2015; 41(1): 81-85. https://doi.org/10.1016/j.gaitpost.2014.08.014.

8. Nadeau $S$, Gravel D, Hebert $L$, Arsenault AB, Lepage Y. Gait study of patients with patellofemoral pain syndrome. Gait Posture 1997; 5(1): 21-27. https://doi.org/10.1016/S0966-6362(96)01078-8.

9. Powers $\mathrm{CM}$, Heino JG, Rao S, Perry J. The influence of patellofemoral pain on lower limb loading during gait. Clin Biomech (Bristol, Avon) 1999; 14(10): 722-728. https://doi.org/10.1016/s0268-0033(99)000194.

10. Powers CM, Perry J, Hsu A, Hislop HJ. Are patellofemoral pain and quadriceps femoris muscle torque associated with locomotor function? Phys Ther 1997; 77(10): 1063-1075. https://doi.org/10.1093/pti/77.10.1063.

11. Levinger $P$, Gilleard $W$. The heel strike transient during walking in subjects with patellofemoral pain syndrome. Phys Ther Sport 2005; 6(2): 83-88. https://doi.org/10.1016/j.ptsp.2005.02.005.

12. Paoloni M, Mangone $M$, Fratocchi G, Murgia M, Saraceni VM, Santilli V. Kinematic and kinetic features of normal level walking in patellofemoral pain syndrome: more than a sagittal plane alteration. $J$ Biomech 2010; 43(9): 1794-1798. https://doi.org/10.1016/j.jbiomech.2010.02.013.

13. Willson JD, Sharpee R, Meardon SA, Kernozek TW. Effects of step length on patellofemoral joint stress in female runners with and without patellofemoral pain. Clin Biomech (Bristol, Avon) 2014; 29(3): 243-247. https://doi.org/10.1016/j.clinbiomech.2013.12.016.

14. Pohl MB, Patel C, Wiley JP, Ferber R. Gait biomechanics and hip muscular strength in patients with patellofemoral osteoarthritis. Gait Posture 2013; 37(3): 440-444 https://doi.org/10.1016/j.gaitpost.2012.08.017.

15. Dillon PZ, Updyke WF, Allen WC. Gait analysis with reference to chondromalacia patellae. J Orthop Sports Phys Ther 1983; 5(3): 127131. https://doi.org/10.2519/jospt.1983.5.3.127.

16. Barton $\mathrm{CJ}$, Levinger $\mathrm{P}$, Webster KE, Menz HB. Walking kinematics in individuals with patellofemoral pain syndrome: a case-control study. Gait Posture 2011; 33(2): 286-291. https://doi.org/10.1016/j.gaitpost.2010.11.022.

17. Skvortsov D, Kaurkin S, Goncharov E, Akhpashev A. Knee joint function and walking biomechanics in patients in acute phase anterior cruciate ligament tear. International Orthopaedics (SICOT) 2020; 44: 885-891. https://doi.org/10.1007/s00264-020-04485-1.

18. Kirtley C. Clinical gait analysis: theory and practice. Edinburgh; New York: Elsevier. 2005; 328 p. https://www.elsevier.com/books/clinicalgait-analysis/9780443100093.

19. Winter D. A. Biomechanics and motor control of human gait: normal, elderly and pathological. 2nd ed. Waterloo, Ont.: University of Waterloo Press, 1991; 143 p.

20. Perry J, Burnfield J. Gait Analysis: Normal and Pathological Function. 2nd Ed. Slack Incorporated, New Jersey, 2010. 551 p.

21. Arazpour M, Bahramian F, Abutorabi A, Nourbakhsh ST, Alidousti A, Aslani H. The Effect of Patellofemoral Pain Syndrome on Gait Parameters: A Literature Review. Arch Bone Jt Surg 2016; 4(4): 298306. https://pubmed.ncbi.nlm.nih.gov/27847840.

22. Levinger $P$, Gilleard $W$. Tibia and rearfoot motion and ground reaction forces in subjects with patellofemoral pain syndrome during walking. Gait $\quad$ Posture 2007; 25(1): $2-8$ https://doi.org/10.1016/j.gaitpost.2005.12.015.

23. Skvortsov DV. Diagnosis of locomotor pathology with toolware: gait analysis, stabilometry. Moscow, Russia: T.M. Andreeva, 2007; 640 p. Russian. https://rehabrus.ru/Docs/Diagn dvig patalogii 2007.pdf.

\section{Authors:}

Aljona V. Altukhova - MD, Research Scientist, Federal Research and Clinical Center of Russian Federal Medical and Biological Agency, Moscow, Russia. https://orcid.org/0000-0003-3777-6294.

Sergey N. Kaurkin - MD, PhD, Senior Research Scientist, Federal Research and Clinical Center of Russian Federal Medical and Biological Agency, Moscow, Russia. https://orcid.org/0000-0001-5232-7740.

Dmitry V. Skvortsov - MD, PhD, Head of the Federal Research and Clinical Center of Russian Federal Medical and Biological Agency, Moscow, Russia; Professor, Department of Rehabilitology and Sports Medicine, Pirogov Russian National Research Medical University, Moscow, Russia. https://orcid.org/0000-0002-2794-4912.

Alexander A. Akhpashev - MD, PhD, Chair of the Department of Traumatology and Orthopedics, Academy of Postgraduate Education at Federal Research and Clinical Center of Russian Federal Medical and Biological Agency; Peoples' Friendship University of Russia, Moscow, Russia. https://orcid.org/0000-0002-2938-5173. 
Nikolay V. Zagorodniy - MD, PhD, Professor, Corresponding Member of RAS; Director of N.N. Priorov National Medical Research Center of Traumatology and Orthopedics, Moscow, Russia. https://orcid.org/00000002-6736-9772. 